\title{
The Factors Affecting the Investors' Decisions: A Study on Nuclear Energy Investments
}

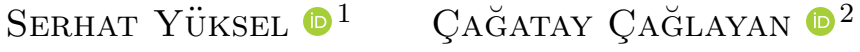 \\ Received: 17.11.2020; Revised: 16.12.2019; Accepted: 18.12.2020
}

\begin{abstract}
The aim of this study is to evaluate the indicators affecting the decision of investors in nuclear energy sector within the scope of behavioral economics. There are two different stages in the analysis process in this paper. First, after a detailed literature review, six different behavioral economics biases are selected as the criteria. Secondly, these factors are weighted for the nuclear energy investors. For this purpose, fuzzy DEMATEL methodology is used. The findings indicate that uncertainty avoidance and overconfidence bias are the most essential factors affecting the decision of investors. Similarly, the mental accounting bias and regret avoidance also have important impacts for this situation. However, loss aversion bias and lack of self-control have the lowest weights for the nuclear energy investors. Additionally, with respect to the impact relation map, it is concluded that uncertainty avoidance is the most influencing issue whereas overconfidence bias is identified as the most influenced factor. Our results suggest that that strategies should be implemented to decrease the anxiety of the nuclear energy investments. For this purpose, governments should take some actions to minimize the uncertainty in the market. For instance, providing loans with low interest rate can minimize interest rate risk. This will probably decrease the anxiety of the nuclear energy investors.
\end{abstract}

JEL codes: O13, P28, Q40

Keywords: Nuclear Energy Investment; Behavioral Economics; Fuzzy DEMATEL

\section{Introduction}

World energy consumption is increasing every year depending on the increasing population and the rate of industrialization. Based on this situation, interest in new energy sources is increasing at the same rate in the world (Yüksel et al., 2019). The main reason is that the exhaustion of fossil fuels

\footnotetext{
1 School of Business, İstanbul Medipol University, Turkey (e-mail: serhatyuksel@medipol.edu.tr).

2 School of Business, İstanbul Medipol University, Turkey (e-mail: cagatay.caglayan@std.medipol.edu.tr).
}

used in energy production and the carbon emission problem requires finding more sustainable energy sources (Zhong et al., 2020). Fossil fuels such as oil and natural gas have provided additional income to the region throughout history. Countries with fossil fuels have reached a great economic power by exporting energy, but the possibility of depletion of fossil fuels threatens the economies of these countries (Qi et al., 2020). The search for more sustainable resources from fossil fuels does not depend solely on the possibility of fossil fuel depletion (Dinçer \& Yüksel, 2019b, 2019a). The carbon emission problem 
caused by fossil fuels is shown as the main cause of global warming. Apart from this, it is stated that fossil fuel use should be reduced since it threatens human health with negative consequences such as air and water pollution.

Renewable energies and nuclear energy are emerging as an alternative to fossil fuels, which are named as non-renewable energy (Zhou et al., 2020). Energies such as the sun, wind and waves constitute renewable energy resources. Since renewable energies do not contain the dangers of fossil fuels, they are very important as an alternative source and promise sustainability. Apart from that, renewable energies also have disadvantages. As an example, energy production from renewable energy sources varies depending on weather conditions, so it would not be wrong to say that renewable energies do not promise uninterrupted energy for 24 hours (Yuan et al., 2020). With this feature, the sustainability of renewable energies can be questioned. Apart from that, economic difficulties are also possible (Qi et al., 2020). Renewable energy investments are very large investments and installation costs are high. Considering the financing problems that investors may experience, it is obvious that the cost is also the disadvantage of renewable energies (Wang et al., 2019).

Another energy source that emerges with the feature of zero carbon emission as an alternative to fossil fuels is nuclear energy. In nuclear power plants, uranium, the element that contains the most protons and neutrons, is used to generate energy (Saidi \& Omri, 2020). Uranium, which is divided by fission, releases a large amount of heat energy. The high heat it generates evaporates the water and turns the turbines. In this way, electricity is produced from the turbines connected to the generator (Luqman et al., 2019). Although all these processes make us think that generating electricity from nuclear power plants is complicated, it can be said that nuclear energy is highly sustainable considering the efficiency and cleaning of the en- ergy obtained (Ağbulut, 2019).

Nuclear energy is one of the most important alternatives that countries keep on the agenda of global warming thanks to its zerocarbon feature and 24-hour uninterrupted electricity generation capacity (Lee, 2020). However, nuclear energy also has some disadvantages. Very high energy is released from nuclear power plants, so there is a risk of explosion in power plants that are not managed well. This scenario can have fatal consequences. In addition, it can be said that the disposal of nuclear waste threatens the environment and human health (Was et al., 2019). By looking at the economic disadvantages, the financing problem arises from the high cost of installation. Nevertheless, nuclear power plants are a very affective energy investment in terms of economy and combating global warming. However, it should be managed by qualified personnel and strict procedures and policies (Kikuchi, 2020).

As mentioned above, nuclear energy projects are quite large investments. Therefore, these investments must be managed well, and the decisions must be taken rationally (Baron \& Herzog, 2020). Thus, the psychological factors, and anomalies in the market, which affect the investment decisions of nuclear energy investors, should be evaluated in terms of behavioral economy (Vo et al., 2020). Therefore, in this study, nuclear energy investments will be evaluated from the perspective of behavioral economy. Within this framework, in the first part, an introduction is given about the future of energy in the world, current energy resources and nuclear energy investments. In the second part, behavioral economics are discussed, and some biases are presented as an example. In the third part, an analysis of biases has been made using DEMATEL method and a summary is presented by discussing the results of the analysis with the last part.

\section{Behavioral economics and biases}

According to classical economic theories, the people are always rational, and every 
person chooses the most rational choices in his preferences. However, it is seen that this assumption is questioned in studies that have survived until today (Streletskaya et al., 2020). Since the day of its existence, a person has been highly affected by external influences. It is as if the human reflects not his own self, but the self-gained by his environment (Arnott \& Gao, 2019). Being influenced by various external environmental issues such as geography, education, belief, and demographic structure, the human being is not completely rational as classical economics assumes. The main reason is that people with ethical values may tend to prioritize their moral ideals more than their financial benefits. Thus, behavioral economics, which claims that man does not always act rationally, is in contradiction with classical economics (Chandra et al., 2019; Kahneman \& Tversky, 2013).

Behavioral economics, which tries to explain how people are affected by social, cognitive, and emotional biases, uses various branches of science to explain the anomalies in the market. Examples of this include psychology and sociology. At this point, Daniel Kahneman has revealed how irrational human beings are, by making strong studies (Kremer et al., 2019). These social, cognitive, and emotional biases are also very effective in nuclear energy investments. Therefore, it is clear that behavioral economics should be used in order to make nuclear energy investment decisions in a more rational environment. An investor who is in a financial decision-making process wants to base his / her opinion on a certain idea and base. Thus, the first knowledge learned about a phenomenon becomes a bias. From an economic point of view, one of the common behave wrongly is to base only a specific data. As an example, an investor who only takes prices as reference will make all future decisions according to this prejudice (Wilson, 2019).

Loss Aversion Bias: Daniel Kahneman put forward this tendency with the "expec- tation theory". According to this bias, every person is more sensitive to losses than earnings. For example, marketing people tell people more about what a product will lose, not what they gain when it is purchased. Focusing on potential losses in this event, the consumer tends to be more willing to buy (Xu et al., 2020).

The Mental Accounting Bias: It seems that the human mind tends to understand various phenomena by categorizing them. This act of categorization causes some problems, in behavioral economics. For instance, the money earned by working and the money received form the parents are quite different. They cause different meanings due to the categorization action of the mind. Therefore, the effect of this bias can be mentioned in nuclear energy investments for the investors (Emami et al., 2020).

Lack of Self-Control: An investor should not deactivate the auto-control circuit of his/her mind because the circuit is the audit mechanism of the human. In the event of a lack of self-control, an investor will tend to spend his pending savings to be used for different purposes, in line with his/her changing ideas. Uncontrolled spending against ideas that seem attractive is a threat to investment decisions (Agbaria \& Bdier, 2019).

Uncertainty Avoidance: Investing in general terms means taking the risk of uncertainty, but the tendency to avoid uncertainty is one of the biases that prevent investment decisions and is common in the economy. Investors with this bias often avoid investing in a new area and prefer to invest in the area they know more (Al-Okaily et al., 2020).

Regret Avoidance: People often tend to avoid regret when making investment decisions because they do not want dissatisfaction at the end of the investment. Investors with this tendency insist on not giving up an investment that causes a loss in order not to regret in the future. In the hope of the day it will win, the investor who insists on his investment may cause more losses due to this bias (Shankar \& Kumari, 2019). 
Overconfidence Bias: The overconfidence bias is one of the dangerous biases, because an overconfident investor sees his/her knowledge as absolute and certain, closing himself/herself to different views. Generally, as knowledge increases, overconfidence decreases, so it can be said that overconfidence is based on ignorance, but people with this tendency are not aware of this situation. With this trend, the investor moves away from objective evaluation and greatly increases the likelihood of failure in his investment (Combrink \& Lew, 2020).

\section{Fuzzy DEMATEL}

DEMATEL methodology is considered to find the significance levels of different factors. In the literature, there are lots of approaches that can be used for this purpose (Du et al., 2020; X. Zhang \& Su, 2019). However, DEMATEL method has some superiorities in comparison with the others. For instance, impact relation map of the factors can be constructed (Mahmoudi et al., 2019; Zhu et al., 2020). Hence, it can be possible to evaluate the causal relationship between the items (Delen et al., 2020). First of all, the purpose of the analysis is determined. Next, some experts are appointed to make evaluations for these factors. In this process, five different scales are considered which are "No", "Low", "Medium", "High", "Very High". After that, direct relation matrix $(\check{Z})$ is constructed (Khan et al., 2019; G. Zhang et al., 2020). For this purpose, the equations (1) and (2) are taken into consideration. In this context, $\check{Z}_{i} j$ indicates the evaluations of the criteria whereas $p$ gives information about the number of experts. They can be represented as triangular fuzzy numbers, such as $\check{Z}_{i j}=\left(l_{i j}, m_{i j}, u_{i j}\right)$.

$$
\begin{gathered}
\check{Z}_{i j}=\frac{\check{Z}^{1} \oplus \check{Z}^{2} \oplus \ldots \check{Z}^{p}}{p} \\
\check{Z}=\left[\begin{array}{ccc}
0 & \cdots & \check{Z}_{1 n} \\
\vdots & \ddots & \vdots \\
\check{Z}_{n 1} & \cdots & 0
\end{array}\right]
\end{gathered}
$$

The next step includes the normalization of the direct relation matrix. This normalized matrix $(\bar{X})$ is created by using the equations $(3)-(5)$.

$$
\begin{gathered}
\bar{X}=\left[\begin{array}{ccc}
\bar{X}_{11} & \cdots & \bar{X}_{1 n} \\
\vdots & \ddots & \vdots \\
\bar{X}_{n 1} & \cdots & \bar{X}_{n n}
\end{array}\right] \\
\bar{X}_{i j}=\frac{\check{Z}_{i j}}{r}\left(\frac{l_{i j}}{r}, \frac{m_{i j}}{r}, \frac{u_{i j}}{r}\right) \\
r=\max _{1 \leq i \leq n}\left(\sum_{j=i}^{n} u_{i j}\right)
\end{gathered}
$$

Later, total relation matrix $(\check{T})$ is constructed with the help of the equations (6) (10).

$$
\begin{gathered}
X_{l}=\left[\begin{array}{ccc}
0 & \cdots & l_{1 n}^{\prime} \\
\vdots & \ddots & \vdots \\
l_{n 1}^{\prime} & \cdots & 0
\end{array}\right] \\
X_{m}=\left[\begin{array}{ccc}
0 & \cdots & m_{1 n}^{\prime} \\
\vdots & \ddots & \vdots \\
m_{n 1}^{\prime} & \cdots & 0
\end{array}\right] \\
X_{u}=\left[\begin{array}{ccc}
0 & \cdots & u_{1 n}^{\prime} \\
\vdots & \ddots & \vdots \\
u_{n 1}^{\prime} & \cdots & 0
\end{array}\right] \\
\check{T}=\left[\begin{array}{ccc}
\check{t}_{11} & \cdots & \check{t}_{1 n} \\
\vdots & \ddots & \vdots \\
\check{t}_{n 1} & \cdots & \check{t}_{n n}
\end{array}\right] \\
w h e r e \check{t}_{i j}=\left(l_{i}^{\prime \prime} j, m_{i}^{\prime \prime} j, u_{i}^{\prime \prime} j\right) \\
l_{i}^{\prime \prime} j=X_{l} \times\left(1-X_{l}\right)^{-1} \\
m_{i}^{\prime \prime} j=X_{m} \times\left(1-X_{m}\right)^{-1} \\
u_{i}^{\prime \prime} j=X_{u} \times\left(1-X_{u}\right)^{-1}
\end{gathered}
$$

Finally, the values of $\left(\check{D}_{l}+\check{R}_{l}\right)^{\text {def }}$ is calculated to identify the weights of the items. Additionally, the value of $\left(\check{D}_{l}-\check{R}_{l}\right)^{\text {def }}$ is computed to generate the impact relation map. In this process, the sum of the rows and columns are demonstrated as $\check{D}_{i}^{\text {def }}$ and $\check{R}_{i}^{\text {def }}$. This methodology was preferred in the literature by lots of researchers (Farooque et al., 2020; Shi et al., 2019; Abdullah et al., 2019; Korsakienè et al., 2020; Pandey et al., 2019; 
Dinçer, Bozaykut-Buk, et al., 2019; Dinçer, Yüksel, \& Çetiner, 2019; Dinçer, Yüksel, \& Martínez, 2019).

\section{Analysis results}

In this study, it is aimed to identify the factors affecting the investors' decisions within the scope of behavioral economics. For this purpose, nuclear energy investors are taken into consideration.

In the analysis process, firstly, 6 different

Table 1: The List of the Criteria

\begin{tabular}{lc}
\hline Criteria & $\begin{array}{c}\text { Supported } \\
\text { Literature }\end{array}$ \\
\hline Loss Aversion Bias (C1) & (Xu et al., 2020) \\
The Mental Accounting & (Emami et al., \\
Bias (C2) & 2020) \\
Lack of Self-Control (C3) & (Agbaria \& Bdier, \\
& 2019) \\
Uncertainty Avoidance & (Al-Okaily et al., \\
(C4) & 2020) \\
Regret Avoidance (C5) & Kumankar \& 2019$)$ \\
Overconfidence Bias (C6) & (Combrink \& Lew, \\
& $2020)$ \\
\hline
\end{tabular}

behavioral economics biases are defined as the criteria. They are detailed on Table 1.

After that, three different experts make evaluations of these factors. These people consist of general managers and academicians. They have at least 16-year experience. In the evaluation process, they consider 5 different scales that are "No", "Low", "Medium", "High", "Very High". The evaluation details of the experts are indicated in Table 2.

After that, these evaluations are converted into triangular fuzzy numbers by considering the values in Table 3.

Hence, the triangular fuzzy numbers of each experts are calculated as in Table 4. By considering these values, direct relation matrix is created. For this purpose, the equations (1) and (2) are taken into consideration. Table 5 demonstrates the details of this matrix. In the next step, normalized matrix is constructed with the help of the equations (3)-(5). This matrix is detailed in Table 6 .
Table 2: The Evaluations of the Experts

\begin{tabular}{|c|c|c|c|c|c|c|}
\hline \multicolumn{7}{|c|}{ Expert1 } \\
\hline Criteria & C1 & C2 & C3 & C4 & C5 & C6 \\
\hline C1 & - & M & VH & $\mathrm{L}$ & $\mathrm{L}$ & M \\
\hline C2 & M & - & M & L & $\mathrm{H}$ & $\mathrm{VH}$ \\
\hline C3 & $\mathrm{L}$ & $\mathrm{H}$ & - & $\mathrm{L}$ & M & M \\
\hline C4 & VH & $\mathrm{VH}$ & VH & - & $\mathrm{VH}$ & $\mathrm{VH}$ \\
\hline C5 & M & M & M & L & - & $\mathrm{VH}$ \\
\hline C6 & $\mathrm{H}$ & M & $\mathrm{H}$ & $\mathrm{L}$ & M & - \\
\hline \multicolumn{7}{|c|}{ Expert2 } \\
\hline Criteria & C1 & C2 & C3 & C4 & C5 & C6 \\
\hline C1 & - & M & $\mathrm{H}$ & $\mathrm{L}$ & M & $\mathrm{L}$ \\
\hline C2 & L & - & $\mathrm{H}$ & L & $\mathrm{H}$ & $\mathrm{H}$ \\
\hline C3 & M & M & - & $\mathrm{L}$ & $\mathrm{L}$ & M \\
\hline C4 & VH & $\mathrm{VH}$ & VH & - & $\mathrm{VH}$ & $\mathrm{VH}$ \\
\hline C5 & M & $\mathrm{H}$ & M & $\mathrm{L}$ & - & $\mathrm{H}$ \\
\hline C6 & $\mathrm{L}$ & M & $\mathrm{H}$ & $\mathrm{L}$ & M & - \\
\hline \multicolumn{7}{|c|}{ Expert3 } \\
\hline Criteria & C1 & C2 & C3 & C4 & C5 & C6 \\
\hline C1 & - & $\mathrm{H}$ & M & $\mathrm{L}$ & $\mathrm{H}$ & M \\
\hline C2 & $\mathrm{L}$ & - & M & $\mathrm{L}$ & M & $\mathrm{H}$ \\
\hline C3 & $\mathrm{L}$ & M & - & $\mathrm{L}$ & $\mathrm{M}$ & $\mathrm{L}$ \\
\hline C4 & VH & $\mathrm{VH}$ & $\mathrm{VH}$ & - & $\mathrm{VH}$ & $\mathrm{VH}$ \\
\hline C5 & $\mathrm{H}$ & M & M & $\mathrm{L}$ & - & $\mathrm{VH}$ \\
\hline C6 & M & M & $\mathrm{H}$ & $\mathrm{L}$ & M & - \\
\hline
\end{tabular}

Table 3: The Evaluations of the Experts

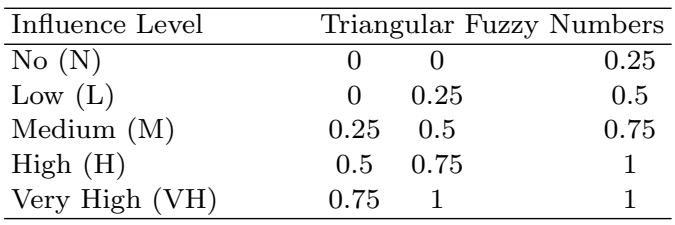

In the next stage, total relation matrix is generated by considering the equations (6) and (7). The details of this matrix are explained in Table 7. After that, the defuzzification process is implemented with the help of the equations (8)-(10). By considering these values, the weights of the criteria are calculated. The details are indicated in Table 8 .

Table 8 states that uncertainty avoidance and overconfidence bias are the most significant criteria. Similarly, the mental accounting bias and regret avoidance also play a key role for this situation. However, loss aversion bias and lack of self-control have the lowest weights for the nuclear energy investors. On the other side, it is also concluded that uncertainty avoidance is the most influencing issue. Nevertheless, overconfidence bias is the most influenced factor. 
Table 4: Triangular Fuzzy Numbers for Experts' Evaluations

\begin{tabular}{|c|c|c|c|c|c|c|c|c|c|c|c|c|c|c|c|c|c|c|}
\hline \multicolumn{19}{|c|}{ Triangular Fuzzy Numbers of Expert 1 for Direct Relation Matrix } \\
\hline \multicolumn{2}{|c|}{ Criteria } & \multicolumn{2}{|l|}{$\mathrm{C} 1$} & \multicolumn{3}{|c|}{$\mathrm{C} 2$} & \multicolumn{3}{|c|}{ C3 } & \multicolumn{3}{|c|}{$\mathrm{C} 4$} & \multicolumn{3}{|c|}{$\mathrm{C} 5$} & \multicolumn{3}{|c|}{ C6 } \\
\hline C1 & 0.00 & 0.00 & 0.00 & 0.25 & 0.50 & 0.75 & 0.75 & 1.00 & 1.00 & 0.00 & 0.25 & 0.50 & 0.00 & 0.25 & 0.50 & 0.25 & 0.50 & 0.75 \\
\hline $\mathrm{C} 2$ & 0.25 & 0.50 & 0.75 & .00 & 0.00 & 0.00 & 0.25 & 0.50 & 0.75 & 0.00 & 0.25 & 0.50 & 0.50 & 0.75 & 1.00 & 0.75 & 1.00 & 1.00 \\
\hline C3 & 0.00 & 0.25 & 0.50 & 0.50 & 0.75 & 1.00 & 0.00 & 0.00 & 0.00 & 0.00 & 0.25 & 0.50 & 0.25 & 0.50 & 0.75 & 0.25 & 0.50 & 0.75 \\
\hline C4 & 0.75 & 1.00 & 1.00 & 0.75 & 1.00 & 1.00 & 0.75 & 1.00 & 1.00 & 0.00 & 0.00 & 0.00 & 0.75 & 1.00 & 1.00 & 0.75 & 1.00 & 1.00 \\
\hline C5 & 0.25 & 0.50 & 0.75 & 0.25 & 0.50 & 0.75 & 0.25 & 0.50 & 0.75 & 0.00 & 0.25 & 0.50 & 0.00 & 0.00 & 0.00 & 0.75 & 1.00 & 1.00 \\
\hline C6 & 0.50 & 0.75 & 1.00 & 0.25 & 0.50 & 0.75 & 0.50 & 0.75 & 1.00 & 0.00 & 0.25 & 0.50 & 0.25 & 0.50 & 0.75 & 0.00 & 0.00 & 0.00 \\
\hline \multicolumn{19}{|c|}{ Triangular Fuzzy Numbers of Expert 2 for Direct Relation Matrix } \\
\hline \multicolumn{2}{|c|}{ Criteria } & \multicolumn{2}{|l|}{$\mathrm{C} 1$} & \multicolumn{3}{|c|}{$\mathrm{C} 2$} & \multicolumn{3}{|c|}{$\mathrm{C} 3$} & \multicolumn{3}{|c|}{$\mathrm{C} 4$} & \multicolumn{3}{|c|}{$\mathrm{C} 5$} & \multicolumn{3}{|c|}{ C6 } \\
\hline C1 & 0.00 & 0.00 & 0.00 & 0.25 & 0.50 & 0.75 & 0.50 & 0.75 & 1.00 & 0.00 & 0.25 & 0.50 & 0.25 & 0.50 & 0.75 & 0.00 & 0.25 & 0.50 \\
\hline $\mathrm{C} 2$ & 0.00 & 0.25 & 0.50 & 0.00 & 0.00 & 0.00 & 0.50 & 0.75 & 1.00 & 0.00 & 0.25 & 0.50 & 0.50 & 0.75 & 1.00 & 0.50 & 0.75 & 1.00 \\
\hline C3 & 0.25 & 0.50 & 0.75 & 0.25 & 0.50 & 0.75 & 0.00 & 0.00 & 0.00 & 0.00 & 0.25 & 0.50 & 0.00 & 0.25 & 0.50 & 0.25 & 0.50 & 0.75 \\
\hline $\mathrm{C} 4$ & 0.75 & 1.00 & 1.00 & 0.75 & 1.00 & 1.00 & 0.75 & 1.00 & 1.00 & 0.00 & 0.00 & 0.00 & 0.75 & 1.00 & 1.00 & 0.75 & 1.00 & 1.00 \\
\hline C5 & 0.25 & 0.50 & 0.75 & 0.50 & 0.75 & 1.00 & 0.25 & 0.50 & 0.75 & 0.00 & 0.25 & 0.50 & 0.00 & 0.00 & 0.00 & 0.50 & 0.75 & 1.00 \\
\hline C6 & 0.00 & 0.25 & 0.50 & 0.25 & 0.50 & 0.75 & 0.50 & 0.75 & 1.00 & 0.00 & 0.25 & 0.50 & 0.25 & 0.50 & 0.75 & 0.00 & 0.00 & 0.00 \\
\hline \multicolumn{19}{|c|}{ Triangular Fuzzy Numbers of Expert 3 for Direct Relation Matrix } \\
\hline \multicolumn{2}{|c|}{ Criteria } & \multicolumn{2}{|l|}{ C1 } & \multicolumn{3}{|c|}{$\mathrm{C} 2$} & \multicolumn{3}{|c|}{ C3 } & \multicolumn{3}{|c|}{$\mathrm{C} 4$} & \multicolumn{3}{|c|}{ C5 } & \multicolumn{3}{|c|}{ C6 } \\
\hline $\mathrm{C} 1$ & 0.00 & 0.00 & 0.00 & 0.50 & 0.75 & 1.00 & 0.25 & 0.50 & 0.75 & 0.00 & 0.25 & 0.50 & 0.50 & 0.75 & 1.00 & 0.25 & 0.50 & 0.75 \\
\hline $\mathrm{C} 2$ & 0.00 & 0.25 & 0.50 & 0.00 & 0.00 & 0.00 & 0.25 & 0.50 & 0.75 & 0.00 & 0.25 & 0.50 & 0.25 & 0.50 & 0.75 & 0.50 & 0.75 & 1.00 \\
\hline C3 & 0.00 & 0.25 & 0.50 & 0.25 & 0.50 & 0.75 & 0.00 & 0.00 & 0.00 & 0.00 & 0.25 & 0.50 & 0.25 & 0.50 & 0.75 & 0.00 & 0.25 & 0.50 \\
\hline $\mathrm{C} 4$ & 0.75 & 1.00 & 1.00 & 0.75 & 1.00 & 1.00 & 0.75 & 1.00 & 1.00 & 0.00 & 0.00 & 0.00 & 0.75 & 1.00 & 1.00 & 0.75 & 1.00 & 1.00 \\
\hline C5 & 0.50 & 0.75 & 1.00 & 0.25 & 0.50 & 0.75 & 0.25 & 0.50 & 0.75 & 0.00 & 0.25 & 0.50 & 0.00 & 0.00 & 0.00 & 0.75 & 1.00 & 1.00 \\
\hline C6 & 0.25 & 0.50 & 0.75 & 0.25 & 0.50 & 0.75 & 0.50 & 0.75 & 1.00 & 0.00 & 0.25 & 0.50 & 0.25 & 0.50 & 0.75 & 0.00 & 0.00 & 0.00 \\
\hline
\end{tabular}

Table 5: Initial Direct Relation Matrix

\begin{tabular}{|c|c|c|c|c|c|c|c|c|c|c|c|c|c|c|c|c|c|c|}
\hline \multicolumn{2}{|c|}{ Criteria } & \multicolumn{2}{|l|}{ C1 } & \multicolumn{3}{|c|}{$\mathrm{C} 2$} & \multicolumn{3}{|c|}{ C3 } & \multicolumn{3}{|c|}{$\mathrm{C} 4$} & \multicolumn{3}{|c|}{ C5 } & \multicolumn{3}{|c|}{ C6 } \\
\hline$\overline{\mathrm{C} 1}$ & 0.00 & 0.00 & 0.00 & 0.33 & 0.58 & 0.83 & .50 & 0.75 & 0.92 & 0.00 & 0.25 & 0.50 & 0.25 & 0.50 & 0.75 & 0.17 & 0.42 & 0.67 \\
\hline $\mathrm{C} 2$ & 0.0 & 33 & 0.58 & 0.00 & 0.00 & 0.00 & 0.33 & 0.58 & 0.83 & 0.00 & 0.25 & 0.50 & 0.42 & 0.67 & 0.92 & 0.58 & 0.83 & 1.00 \\
\hline C3 & 0.08 & 0.33 & 58 & 0.33 & 0.58 & 0.83 & 0.00 & 0.00 & 0.00 & 0.00 & 0.25 & 0.50 & 0.17 & 0.42 & 0.6 & 0.17 & 0.42 & 0.67 \\
\hline $\mathrm{C} 4$ & 0.75 & 1.00 & 1.00 & 0.75 & 1.00 & 1.00 & 0.75 & 1.00 & 1.00 & 0.0 & 0.00 & 0.00 & 0.75 & 1.00 & 1.00 & 0.75 & 1.00 & 1. \\
\hline C5 & 0.33 & 0.58 & .83 & 0.33 & 0.58 & 0.83 & 0.25 & 0.50 & 0.75 & 0.00 & 0.25 & 0.50 & 0.00 & 0.00 & 0.00 & 0.67 & 0.92 & 1.00 \\
\hline C6 & 0.25 & 0.50 & 0.75 & 0.25 & 0.50 & 0.75 & 0.50 & 0.75 & 1.00 & 0.00 & 0.25 & 0.50 & 0.25 & 0.50 & 0.75 & 0.00 & 0.00 & 0.00 \\
\hline
\end{tabular}

Table 6: Normalized Matrix

\begin{tabular}{lllllllllllllllllllllll}
\hline \multicolumn{2}{l}{ Criteria } & C1 & \multicolumn{1}{c}{ C2 } & \multicolumn{1}{c}{ C3 } & & & C4 & & C5 & & C6 \\
\hline C1 & 0.00 & 0.00 & 0.00 & 0.07 & 0.12 & 0.17 & 0.10 & 0.15 & 0.18 & 0.00 & 0.05 & 0.10 & 0.05 & 0.10 & 0.15 & 0.03 & 0.08 & 0.13 \\
C2 & 0.02 & 0.07 & 0.12 & 0.00 & 0.00 & 0.00 & 0.07 & 0.12 & 0.17 & 0.00 & 0.05 & 0.10 & 0.08 & 0.13 & 0.18 & 0.12 & 0.17 & 0.20 \\
C3 & 0.02 & 0.07 & 0.12 & 0.07 & 0.12 & 0.17 & 0.00 & 0.00 & 0.00 & 0.00 & 0.05 & 0.10 & 0.03 & 0.08 & 0.13 & 0.03 & 0.08 & 0.13 \\
C4 & 0.15 & 0.20 & 0.20 & 0.15 & 0.20 & 0.20 & 0.15 & 0.20 & 0.20 & 0.00 & 0.00 & 0.00 & 0.15 & 0.20 & 0.20 & 0.15 & 0.20 & 0.20 \\
C5 & 0.07 & 0.12 & 0.17 & 0.07 & 0.12 & 0.17 & 0.05 & 0.10 & 0.15 & 0.00 & 0.05 & 0.10 & 0.00 & 0.00 & 0.00 & 0.13 & 0.18 & 0.20 \\
C6 & 0.05 & 0.10 & 0.15 & 0.05 & 0.10 & 0.15 & 0.10 & 0.15 & 0.20 & 0.00 & 0.05 & 0.10 & 0.05 & 0.10 & 0.15 & 0.00 & 0.00 & 0.00 \\
\hline
\end{tabular}

Table 7: Total Relation Matrix

\begin{tabular}{lllllllllllllllllllllll}
\hline Criteria & C1 & \multicolumn{1}{c}{ C2 } & \multicolumn{1}{c}{ C3 } & \multicolumn{1}{c}{ C } \\
\hline C1 & 0.01 & 0.10 & 0.40 & 0.08 & 0.22 & 0.59 & 0.12 & 0.26 & 0.63 & 0.00 & 0.10 & 0.38 & 0.06 & 0.20 & 0.57 & 0.06 & 0.21 & 0.58 \\
C2 & 0.03 & 0.17 & 0.52 & 0.02 & 0.12 & 0.47 & 0.09 & 0.24 & 0.64 & 0.00 & 0.10 & 0.39 & 0.10 & 0.24 & 0.61 & 0.14 & 0.29 & 0.65 \\
C3 & 0.02 & 0.14 & 0.47 & 0.07 & 0.20 & 0.55 & 0.01 & 0.11 & 0.43 & 0.00 & 0.09 & 0.35 & 0.04 & 0.17 & 0.51 & 0.05 & 0.19 & 0.54 \\
C4 & 0.18 & 0.36 & 0.70 & 0.20 & 0.40 & 0.77 & 0.21 & 0.42 & 0.80 & 0.00 & 0.10 & 0.38 & 0.19 & 0.39 & 0.74 & 0.21 & 0.42 & 0.78 \\
C5 & 0.08 & 0.21 & 0.57 & 0.09 & 0.24 & 0.62 & 0.08 & 0.24 & 0.64 & 0.00 & 0.11 & 0.39 & 0.02 & 0.12 & 0.46 & 0.15 & 0.30 & 0.66 \\
C6 & 0.06 & 0.19 & 0.54 & 0.07 & 0.21 & 0.59 & 0.12 & 0.26 & 0.65 & 0.00 & 0.10 & 0.38 & 0.06 & 0.20 & 0.57 & 0.02 & 0.13 & 0.47 \\
\hline
\end{tabular}


Table 8: Total Relation Matrix

\begin{tabular}{lccc}
\hline Criteria & Di+Ri & Di-Ri & Weights \\
\hline Loss Aversion Bias (C1) & 2.808 & -0.079 & 0.1538 \\
$\begin{array}{l}\text { The Mental Accounting } \\
\text { Bias (C2) }\end{array}$ & 3.106 & -0.221 & 0.1701 \\
$\begin{array}{l}\text { Lack of Self-Control } \\
\text { (C3) }\end{array}$ & 2.967 & -0.621 & 0.1626 \\
$\begin{array}{l}\text { Uncertainty Avoidance } \\
\text { (C4) }\end{array}$ & 3.128 & 1.408 & 0.1714 \\
$\begin{array}{l}\text { Regret Avoidance (C5) } \\
\begin{array}{l}\text { Overconfidence Bias } \\
\text { (C6) }\end{array}\end{array}$ & 3.091 & -0.095 & 0.1693 \\
\hline & & -0.393 & 0.1728 \\
\hline
\end{tabular}

\section{Discussion and conclusion}

In this study, it is intended to define the indicators affecting the investors' decisions within the scope of behavioral economics. In this framework, nuclear energy investors are taken into consideration. The analysis process has two different stages. Firstly, 6 different behavioral economics biases are selected as the criteria. After that, these factors are weighted for the nuclear energy investors. Within this framework, fuzzy DEMATEL methodology is used. It is identified that uncertainty avoidance and overconfidence bias are the most essential factors. Additionally, the mental accounting bias and regret avoidance also have an important impact for this situation. Nonetheless, loss aversion bias and lack of self-control have the lowest weights for the nuclear energy investors. Moreover, it is also defined that uncertainty avoidance is the most influencing issue whereas overconfidence bias is identified as the most influenced factor.

Nuclear energy investments are important for the economic development of countries. These energy types have very serious advantages. First of all, as a result of the use of nuclear energy, no carbon gas is released into the atmosphere. This stated situation prevents the environmental pollution problem. This will significantly reduce the number of sick people. This will contribute to the increase in the workforce in the country. In addition, this helps to reduce healthcare spending. This will positively affect the country's budget balance. On the other hand, coun- tries will have their own energy resources thanks to the use of nuclear energy. This will reduce countries' dependence on foreign countries on energy.

As can be seen, the increase in nuclear energy investments is very important for the country. In this context, incentives to be given by the state are very important. However, the profile of nuclear energy investors also needs to be analyzed. In this study, profiles of nuclear energy investors are evaluated. It is understood that nuclear energy investors are afraid of uncertainty. Because of this problem, they are not willing to make investments in nuclear energy projects when they feel anxious. Moreover, when the nuclear energy investors increase their knowledge about this situation, they tend to be closing himself/herself to different views. Hence, necessary actions should be taken to minimize these problems.

For this purpose, strategies should be implemented to decrease the anxiety of the nuclear energy investors. In this scope, governments should take some actions to minimize the uncertainty in the market. For example, credits should be provided to the nuclear energy investors with a lower interest rate. With the help of this actions, interest rate risk can be minimized. In other words, these investors cannot be affected from the volatility in the interest rates. The main limitation of this study is to focus on only nuclear energy projects. In the following studies, different energy types can be taken into consideration. For example, renewable energy projects can be evaluated.

\section{References}

Abdullah, L., Zulkifli, N., Liao, H., Herrera-Viedma, E., \& Al-Barakati, A. (2019). An intervalvalued intuitionistic fuzzy DEMATEL method combined with Choquet integral for sustainable solid waste management. Engineering Applications of Artificial Intelligence, 82, 207-215. doi:10.1016/j.engappai.2019.04.005

Ağbulut, . (2019). Turkey's electricity generation problem and nuclear energy policy. Energy Sources, Part A: Recovery, Utilization, 
and Environmental Effects, 41(18), 2281-2298. doi:10.1080/15567036.2019.1587107

Agbaria, Q., \& Bdier, D. (2019). The Role of Self-Control and Identity Status as Predictors of Internet Addiction among Israeli-Palestinian College Students in Israel. International Journal of Mental Health and Addiction, 1-15. doi:10.1007/s11469-019-00172-4

Al-Okaily, M., Lutfi, A., Alsaad, A., Taamneh, A., \& Alsyouf, A. (2020). . Technology in Society, 63, 101367. doi:10.1016/j.techsoc.2020.101367

Arnott, D., \& Gao, S. (2019). Behavioral economics for decision support systems researchers. Decision Support Systems, 122, 113063. doi:10.1016/j.dss.2019.05.003

Baron, J., \& Herzog, S. (2020). Public opinion on nuclear energy and nuclear weapons: The attitudinal nexus in the United States. Energy Research \&3 Social Science, 68, 101567. doi:10.1016/j.erss.2020.101567

Chandra, A., Handel, B., \& Schwartzstein, J. (2019). Behavioral economics and health-care markets. In Handbook of behavioral economics: Applications and foundations 1 (Vol. 2, pp. 459-502). NorthHolland. doi:10.1016/bs.hesbe.2018.11.004

Combrink, S., \& Lew, C. (2020). Potential underdog bias, overconfidence and risk propensity in investor decision-making behavior. Journal of Behavioral Finance, 21(4), 337-351. doi:10.1080/15427560.2019.1692843

Delen, D., Dorokhov, O., Dorokhova, L., Dinçer, H., \& Yüksel, S. (2020). Balanced scorecardbased analysis of customer expectations for cosmetology services: a hybrid decision modeling approach. Journal of Management Analytics, 1-32. doi:10.1080/23270012.2020.1818319

Dinçer, H., Bozaykut-Buk, T., Emir, ., Yuksel, S., \& Ashill, N. (2019). Using the fuzzy multicriteria decision making approach to evaluate brand equity: a study of privatized firms. Journal of Product \&s Brand Management. doi:10.1108/JPBM09-2018-2037

Dinçer, H., \& Yüksel, S. (2019a). Balanced scorecard-based analysis of investment decisions for the renewable energy alternatives: A comparative analysis based on the hybrid fuzzy decisionmaking approach. Energy, 175, 1259-1270. doi:10.1016/j.energy.2019.03.143

Dinçer, H., \& Yüksel, S. (2019b). Multidimensional evaluation of global investments on the renewable energy with the integrated fuzzy decisionmaking model under the hesitancy. International Journal of Energy Research, 43(5), 1775-1784. doi:10.1002/er.4400

Dinçer, H., Yüksel, S., \& Çetiner, . T. (2019). Strategy selection for organizational performance of Turkish banking sector with the integrated multidimensional decision-making approach. In Handbook of research on contemporary approaches in management and organizational strategy (pp. 273-291). IGI Global. doi:10.4018/978-1-52256301-3.ch014

Dinçer, H., Yüksel, S., \& Martínez, L. (2019).
Interval type 2-based hybrid fuzzy evaluation of financial services in E7 economies with DEMATEL-ANP and MOORA methods. Applied Soft Computing, 79, 186-202. doi:10.1016/j.asoc.2019.03.018

Du, L., Dinçer, H., Ersin, ., \& Yüksel, S. (2020). IT2 Fuzzy-Based Multidimensional Evaluation of Coal Energy for Sustainable Economic Development. Energies, 13(10), 2453. doi:10.3390/en13102453

Emami, A., Welsh, D. H., Ramadani, V., \& Davari, A. (2020). The impact of judgment and framing on entrepreneurs' decision-makin. Journal of Small Business \&6 Entrepreneurship, 32(1), 79100. doi:10.1080/08276331.2018.1551461

Farooque, M., Jain, V., Zhang, A., \& Li, Z. (2020). 1 10.1016/j.cie.2020.106684, 147, 106684. doi:10.1016/j.cie.2020.106684

Kahneman, D., \& Tversky, A. (2013). Prospect theory: An analysis of decision under risk. In Handbook of the fundamentals of financial decision making: Part $i$ (pp. 99-127). World Scientific. doi:10.1142/9789814417358_0006

Khan, S., Khan, M. I., \& Haleem, A. (2019). Evaluation of barriers in the adoption of halal certification: a fuzzy DEMATEL approach. Journal of Modelling in Management, 14(1), 153-174. doi:10.1108/JM2-03-2018-0031

Kikuchi, M. (2020). Changing dynamics of the nuclear energy policy-making process in Japan. Environmental Policy and Governance. doi:10.1002/eet.1922

Korsakienè, R., Raišienè, A. G., Dinçer, H., Yüksel, S., \& Aleksejevec, V. (2020). Strategic Mapping of Eco-innovations and Human Factors: Business Projects' Success Revisited. In Strategic outlook for innovative work behaviours (pp. 1-19). Springer, Cham. doi:10.1007/978-3-030-501310_1

Kremer, M., Rao, G., \& Schilbach, F. (2019). Behavioral development economics. In Handbook of behavioral economics: Applications and foundations 1 (Vol. 2, pp. 345-458). North-Holland.

Lee, T. (2020). From nuclear energy developmental state to energy transition in South Korea: The role of the political epistemic community. Environmental Policy and Governance. doi:10.1002/eet.1919

Luqman, M., Ahmad, N., \& Bakhsh, K. (2019). Nuclear energy, renewable energy and economic growth in Pakistan: Evidence from non-linear autoregressive distributed lag model. Renewable Energy, 139, 1299-1309. doi:10.1016/j.renene.2019.03.008

Mahmoudi, S., Jalali, A., Ahmadi, M., Abasi, P., \& Salari, N. (2019). Identifying critical success factors in Heart Failure Self-Care using fuzzy DEMATEL method. Applied Soft Computing, 84, 105729. doi:10.1016/j.asoc.2019.105729

Pandey, M., Litoriya, R., \& Pandey, P. (2019). Identifying causal relationships in mobile app issues: An interval type-2 fuzzy DEMATEL approach. Wireless Personal Communications, 
108(2), 683-710. doi:10.1007/s11277-019-064249

Qi, W., Huang, Z., Dinçer, H., Korsakienè, R., \& Yüksel, S. (2020). Corporate Governance-Based Strategic Approach to Sustainability in Energy Industry of Emerging Economies with a Novel Interval-Valued Intuitionistic Fuzzy Hybrid Decision Making Model. Sustainability, 12(8), 3307. doi:10.3390/su12083307

Saidi, K., \& Omri, A. (2020). Reducing $\mathrm{CO} 2$ emissions in OECD countries: Do renewable and nuclear energy matter? Progress in Nuclear Energy, 126, 103425. doi:10.1016/j.pnucene.2020.103425

Shankar, A., \& Kumari, P. (2019). Exploring the enablers and inhibitors of electric vehicle adoption intention from sellers' perspective in India: A view of the dual-factor model. International Journal of Nonprofit and Voluntary Sector Marketing, 24(4), e1662. doi:10.1002/nvsm.1662

Shi, X., Li, J., Wang, F., Dinçer, H., \& Yüksel, S. (2019). A hybrid decision-making approach for the service and financial-based measurement of universal health coverage for the E7 economies. International journal of environmental research and public health, 16 (18), 3295. doi:10.3390/ijerph16183295

Streletskaya, N. A., Bell, S. D., Kecinski, M., Li, T., Banerjee, S., Palm-Forster, L. H., \& Pannell, D. (2020). Agricultural adoption and behavioral economics: Bridging the gap. Applied Economic Perspectives and Policy, 42(1), 54-66. doi:10.1002/aepp.13006

Vo, D. H., Vo, A. T., Ho, C. M., \& Nguyen, H. M. (2020). The role of renewable energy, alternative and nuclear energy in mitigating carbon emissions in the CPTPP countries. Renewable Energy, 161, 278-292. doi:10.1016/j.renene.2020.07.093

Wang, S., Liu, Q., Yuksel, S., \& Dincer, H. (2019). Hesitant linguistic term sets-based hybrid analysis for renewable energy investments. IEEE Access, 7, 114223-114235. doi:10.1109/ACCESS.2019.2935427

Was, G. S., Petti, D., Ukai, S., \& Zinkle, S. (2019). Materials for future nuclear energy systems. Journal of Nuclear Materials, 527, 151837. doi:10.1016/j.jnucmat.2019.151837

Wilson, T. (2019). The promise of behavioral economics for understanding decision-making in the court. Criminology \& Public Policy, 18(4), 785805. doi:10.1111/1745-9133.12461

Xu, P., Van Dam, N. T., van Tol, M. J., Shen, X., Cui, Z., Gu, R., ... Luo, Y. J. (2020). Amygdala-prefrontal connectivity modulates loss aversion bias in anxious individuals. NeuroImage, 116957. doi:10.1016/j.neuroimage.2020.116957

Yüksel, S., Dinçer, H., \& Meral, Y. (2019). Financial analysis of international energy trade: a strategic outlook for EU-15. Energie, 12(3), 431. doi:10.3390/en12030431

Yuan, J., Zhang, Z. M., Yüksel, S., \& Dinçer, H. (2020). Evaluating recognitive bal- anced scorecard-based quality improvement strategies of energy investments with the integrated hesitant 2-tuple interval-valued pythagorean fuzzy decision-making approach to QFD. IEEE Access, 8, 171112-171128. doi:10.1109/ACCESS.2020.3023330

Zhang, G., Zhou, S., Xia, X., Yüksel, S., Baş, H., \& Dincer, H. (2020). Strategic Mapping of Youth Unemployment With Interval-Valued Intuitionistic Hesitant Fuzzy DEMATEL Based on 2-Tuple Linguistic Values. IEEE Access, 8, 25706-25721. doi:10.1109/ACCESS.2020.2971102

Zhang, X., \& Su, J. (2019). A combined fuzzy DEMATEL and TOPSIS approach for estimating participants in knowledge-intensive crowdsourcing. Computers 83 Industrial Engineering,, 137, 106085. doi:10.1016/j.cie.2019.106085

Zhong, J., Hu, X., Yüksel, S., Dinçer, H., \& Ubay, G. G. (2020). Analyzing the investments strategies for renewable energies based on multi-criteria decision model. IEEE Access, 8, 118818-118840. doi:10.1109/ACCESS.2020.3005064

Zhou, P., Zhou, P., Yüksel, S., Dinçer, H., \& Uluer, G. S. (2020). Balanced scorecard-based evaluation of sustainable energy investment projects with it2 fuzzy hybrid decision making approach. Energies, 13(1), 82. doi:10.3390/en13010082

Zhu, L., Hu, L., Yüksel, S., Dinçer, H., Karakus, H., \& Ubay, G. G. (2020). Analysis of Strategic Directions in Sustainable Hydrogen Investment Decisions. Sustainability, 12(11), 4581. doi:10.3390/su12114581 